\section{RECENT SEISMOLOGY.}

II.-Unfelt Movenents of The EARTh'S CRUST. THE records obtained from seismographs often showed, as we have already explained, preliminary vibra tions performed with a rapidity which has even reached fifteen complete back and forth movements per second, a shock or shocks, and lastly a number of irregular jolts or

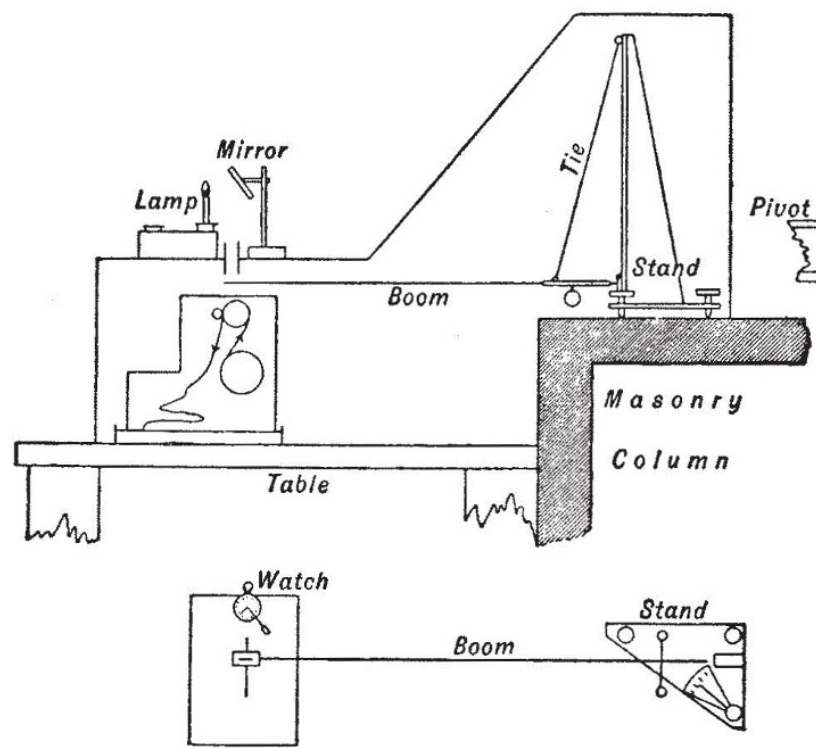

F1G. 7.-Type of instrument adopted by the Seismological Investigation Committee of the British Association, and established at many stations round the world. (Milne.)

undulations which died away with an increasing period. What seismologists had captured was what they could feel, and they were left to speculate as to what came at either extremity of the seismic spectrum. It seemed tolerably certain that if instruments were constructed capable of responding to exceedingly rapid but minute elastic vibrations, then a seismogran might show the movements preceding but forming portions of the preliminary vibrations. These would ac company the sound waves which in rocky districts so commonly outrace movements of a more pronounced character. These sound phenomena, which never extend far beyond an epifocal area, are in certain districts isolated phenomena which frequently recur. Without calling up the "spooks of Ballechin," or the Ghost of Long Wittenham, which on New Year's Eve rapped on the walls of many houses, in two instances we are assured that they have been sufficient to explain noises which had been regarded as supernatural, and it is not unlikely that the fully-equipped ghost hunter may be the discoverer of new paths in seismic science. When a volcano explodes, the resultant vibrations to which ordinary seismographs or ourselves are sensible, seldom reach to any great clistance; but is it not possible that elastic tremors, the result of a powerful impulse. may even reach and be focussed at

$$
1 \text { Continued from p. } 249 \text {. }
$$

the antipodes of their origin? In the Perry-tromometer we have an apparatus which will automatically record elastic vibrations of the order here considered, but up to the present we are without the observer who is able to isolate himself at a site suitable for its installation. In the Isle of Wight the writer found that this instrument recorded the firing of cannon at a distance of six miles, the movements of trains at a distance of nearly one mile, the rumbling of carriages at the distance of a quarter of a mile, whilst it kept an excellent tally of the back and forth journeys of eleven gravel carts worked by a neighbouring contractor.

Investigations on the other end of the seismic spectrum have been more successful, and we now know that waves which have a period of one or two seconds within the area where they are appreciable to the senses, after these have radiated to great distances, for example over or through a quadrant of the earth, their period may exceed twenty seconds. In consequence of the slowness of the movements, together with the flatness of the waves, which are probably miles in length with heights measured by a few inches, every city in the world is often rocked slowly to and fro, and yet to the unaided senses motion is imperceptible.

A form of instrument used by the writer to record unfelt earthquakes, diurnal waves, tremors and other movements is shown in Fig. 7. On the outer end of the boom of the pendulum there is a small aluminium plate in which there is a slit. This is free to float to the right or left over a slit in the lid of a box in which clockwork drives a band of bromide paper. Light from a lamp passing through the two crossed slits reaches the paper as a point, and gives a line with extremely fine definition (see Fig. 8, under the words September 21). At each half-hour the minute hand of a watch crosses one end of the slit, and by eclipsing the light gives the hour marks shown in Fig. 8.

In the photograms of these unfelt earthquakes we see that the duration of the preliminary tremors is apparently connected with the distance the disturbance has travelled, and in this way a record has impressed upon it what is partially equivalent to the post-mark of its origin. For example, a disturbance originating in Japan would at a

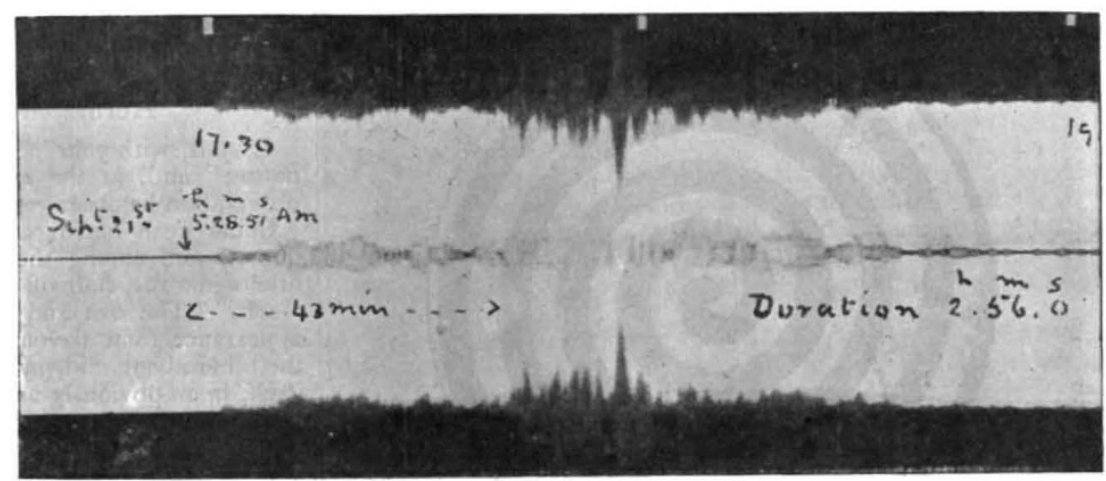

FIG. 8,--This earthquake of September $2 x, 1897$, as recorded in the Isle of Wight, shows preliminary tremors of about 43 minutes, which indicate an origin at a distance of $112^{\circ}$, say, east of Borneo. It disfurbed
magnetographs in Batavia. A similar eartbquake ten hours earlier is not known to have done so. (Milne.) distance of, say, $200 \mathrm{~km}$., be heralded by tremors which an ordinary seismograph would show to have a duration of ten or twenty seconds. A seismogram of the same shock taken in Europe shows that the same movements have a duration of about half an hour. The maxima phases of movements, which may be waves of distortion modified by gravity, travel at approximately 
the same rate of 2 or $3 \mathrm{~km}$. per second over paths which are long or short. The preliminary vibrations, in all likelihood representing waves of compression, appear to have velocities of propagation closely related to the length of the path as measured on an arc over or across which they have been propagated. Such figures as we have, which are open to correction after observations have been extended, are easily remembered. Starting with a velocity of $2 \mathrm{~km}$. per second for a path of $2000 \mathrm{~km}$., then for a path of $4000 \mathrm{~km}$. the velocity would be $4 \mathrm{~km}$. per second, from Japan to England, or 9000 $\mathrm{km}$., the velocity would be $9 \mathrm{~km}$. per second; whilst, if we may carry conclusions beyond the limits of observation, we may imagine that the velocity of propagation between an origin and its antipodes may be $18 \mathrm{~km}$. per second. As Mr. J. Larmor pointed out, if our records are correct, then outside our first $2000 \mathrm{~km}$. coseismal, great disturbances will be recorded at all points on the surface of the world at approximately the same instant. Undoubtedly velocities of 9 and $10 \mathrm{~km}$. per second have been noted, which indicate that the preliminary vibrations, at least, can not have been transmitted round the heterogeneous and broken materials constituting the earth's crust, but rather, that the movements have passed along direct, or by refraction along curvilinear paths through the interior of our earth. This fact, taken in conjunction with the fact that velocities of transmission increase with an increase in the length of the wave path, and that at any given station two sets of vibration separated by a time interval proportional to the difference in the great circle distances between an epicentre and the point of observation have not been observed, tend to strengthen this same view.

Rules connected with the transmission of preliminary tremors which apparently promise to throw new light on the physical condition of the interior of the earth are-.

(I) The velocity in kilometres per second with which these movements are propagated is equal to one-quarter of the square root of the mean depth of the chord or path (in kilometres) along which we may suppose they travelled.

(2) The duration of preliminary tremors, or the interval of time expressed in minutes by which they outrace the longer period waves (as shown on a seismogram), equals the square root of the mean depth of the supposed wave path expressed in kilometres.

These rules, taken in conjunction with a map showing the surface configuration of the globe, enable an individual observer not only to locate an origin but also to determine the time at which an earthquake originated.

Inasmuch as a Committee of the British Association have lent their weight to the establishment of a number of horizontal pendulums at various observatories around the world, within the next few years it is likely that our present knowledge of the seismic breathings of the earth's crust will be placed on a more extended and accurate basis than that on which it at present rests; and, amongst other things, we shall have accumulated new facts bearing upon the effective rigidity of our planet, which is evidently greater than that usually assumed.

The practical outcome of this work is already manysided. Observers at magnetic observatories, like those at Kew, Potsdam and Batavia, are now aware that greater or less disturbances in the uniformity of their records sometimes accompany unfelt earth waves. Because the earth waves do not always leave a record of their occurrence, whilst there are magnetographs of the Kew type, as, for example, at Greenwich, Falmouth and Stonyhurst, which, so far as I can learn, are but very rarely disturbed, we can not say with certainty that the movements of magnetometers are altogether the effect of mechanical disturbance. At about 5 á.m. on September $2 \mathrm{I}$, very marked movements were recorded by the magnetographs in Batavia, evidently the result of a movement recorded in the Isle of Wight (see Fig. 8). Because the preliminary tremors have a duration of forty-three minutes, the distance of their origin from the south of England is probably about 1 I $2^{\circ}$. This, together with the fact that on this date a "slight tremor" was felt along the coast of North Borneo, makes it tolerably certain that the origin of this convulsion was one or two hundred miles from that island. Strange to say, at $7 \mathrm{p} \mathrm{m}$. on the previous evening a disturbance, in all its main features identical with the one here illustrated, is also to be seen on the Isle of Wight seismograms, from which it may be inferred that we have the records of two earthquakes from the same origin.

Assuming this to be the case then, so far as we can judge from information received from Batavia, it was only the second of these unfelt motions that caused disturbances in the magnetographs at that place. Not only are magnetographs affected at the time when huge earth waves slowly move the areas on which they are situated, but in Japan similar instruments situated near to an earthquake centrum have been perturbed some days before the occurrence of a world-shaking shock. Then, again, there are the remarkable secular changes in declination and dip observed between 1880 and 1885 , at several eastern stations, respecting which Captain E. W. Creak, F.R S., gives the following notes:-

Bombay.-Until $1883-85$ the needle was moving eastwards. It then stopped, since which it has been moving westwards at an increasing rate. In I88I there was a sudden change in the dip, and the needle is now going down.

Hong Kong.-Until 1875 the needle was moving eastwards. Then there was a rest until 1880 , when it turned westwards. The dip was upwards until about I 880 , since which it has turned downwards.

Batavia.-Until 1884 the needle was moving eastwards, when it became stationary. It is now moving westwards. The dip was moderately upwards until $188 \mathrm{r}$, but it has now greatly increased.

When it is remembered that these remarkable changes took place about the time of large earthquakes in Japan, as, for example, that which led to the inauguration of the Seismological Society in 1880 , the Krakatoa eruption of 1883 , and that the illustrations of more immediate possible connections between seismic and magnetic phenomena may be multiplied, we recognise that the seismic survey of the world may not only throw new light upon its physical condition, but also, perhaps, it may lead to inferences respecting gravitational rearrangements of external materials and internal magmas. The sites of these, at present, hypothetical hypogenic changes we should expect to find in districts where secular movements and superficial loading, due to sedimentation, are most pronounced. Because earthquakes are apparently the results of critical conditions in these processes, the records from horizontal pendulums tell us that the sites we search for are to be found submerged beneath deep water at or near the base of steeply sloping continental areas. The enormous size of the superficial displacements which accompany certain of these suboceanic changes is indicated by the creation of sea-waves, which have often agitated the whole of the Pacific for a period of one or two days; and if these rearrangements of material on the bed of an ocean are related to changes in the state of stress or accelerations in the movement of an internal quasi rigid matter influenced by continental load, we see in the operations which culminate as earthquakes, causes which should, at least, have a local magnetic influence.

Captain Creak, writing on "the general bearing of magnetic observations," in Science Progress, April I896, says : "It may be remarked in passing that a remarkable alteration in the ansount of secular change has been noticed in the declination and inclination at the following 
observatories: Bombay, Batavia and Hong Kong, about the period of the eruption of Krakatoa in $188_{3}$. This may be only a coincidence, but may it not also point to the possibility that the changes below the surface of the earth which culminated in that mighty explosion, and may still be at work, have had and continues to have magnetic effects which are recorded by the needles at these observatories?" (See also "The Volcanoes of Japan," by J. Milne, Trans. Seis. Soc., vol. ix. part 2, p. 178, I 886.)

The seismograms of unfelt earthquakes tell the student of dynamical geology that certain activities to which he devotes attention are more pronounced beneath the ocean than they are on land, whilst the location of the origins from which these movements proceed indicate to the cable engineer districts to be avoided.

If we except the action of waves, the barings of teredo, and other influences resulting in cable destruction in shallow water, submarine earthquakes and their accompanying land-slides are responsible for very many interruptions of international communication. This form of destruction is particularly marked along the west coast of South America, and it is not unknown in the Atlantic, the Mediterranean, and the Indian Ocean. In I888 a submarine earthquake cut off the Australian colonies from the outer world for a period of nineteen days, and the apprehension that the isolation was an act of war led to the calling out of military and naval reserves. $\mathrm{Had}$ Australia been provided with a single instrument to record the unfelt movements, which must have reached it, anxiety and expense would have been avoided.

From an official notification I learn that two West Indian cables gave way on December 3I, I897. I am not certain, but the Isle of Wight seismograms indicate that the failures probably took place at II.30 a.m.. G.M.T., on December 29.

One immediate use of a seismogram is that it tells us whenever a large earthquake occurs, and gives a locus for its origin, which information has already on more than one occasion been the means of correcting, confirming, extending and disproving ordinary telegraphic information. Sometimes messages have reached us which have contained errors in their dates of one or two days, others have been grossly exaggerated accounts of small disturbances, whilst a third group, inasmuch as they create feelings of anxiety without reason are the most reprehensible of all, have, if we except the feelings of satisfaction they gave to their senders, been without foundation. In all these instances the seismogram or its absence has assisted in the interpretation of the telegram.

Up to the present seismology has found foster-parents in the meteorologist and the geologist-the one collecting facts about earthquakes, whilst the other wrote about them. Because it has grown to unwieldy proportions, it seems time that the child should try and stand alone and become guardian of its own discoveries. In "diurnal waves" and "tremors" we see Romulus and Remus seeking a mother, and although they are not of the genus terrcemotus, because they partially, at least, represent earth-movements, Seismology has become their guardian.

By a diurnal wave we mean a slow tilting which takes place in piers and buildings, especially on fine days, for six or ten hours rapidly in one direction, and during the remainder of the twenty-four hours, but more slowly, in an opposite direction (Fig. 9). This movement may be found underground where changes in temperature are insignificant. The actual causes of these movements are at present matters for speculation, but the theory which best explains the phenomena they present (as for example, that on opposite sides of a valley, it has been observed that movements take place simultaneously but in opposite direction), is that these changes in the vertical are due to differential changes on opposite sides of a station in the loads removed during the day, or acquired during the night by evaporation and condensation of aqueous vapours. During the day it is assumed that, by ordinary evaporation and the transpiration of plants, the bottom of a valley loses more weight than its comparatively drier and less clothed sides.

During a hot day the stream at the bottom of such a valley should discharge fewer and fewer gallons of water, whilst the valley bed, because it is relieved of load, should rise. For the remaining fourteen or eighteen hours, because aqueous vapour is condensed beneath the chilled surface of the ground, or as it emerges from the ground on plant and other surfaces, the stream in the bottom of the valley would increase its flow, and relatively to the sides and bounding ridges of the valley, where we may suppose the conditions for condensation to be less favourable, the lower parts of the same would become heavier and thereby sink. As to whether this concertina-like opening and shutting of valleys representing changes of slope of one or two inches in three or four miles in the average inclination of their boundaries really exists, all we can say is that instruments have given indications that can be explained on such a supposition. The fact that the piers carrying some of the instruments have risen from the chalk, and not from the alluvium, and that during long-continued wet weather there is continuous creeping of a horizontal pendulum towards the heavily loaded valley bottom, and that the

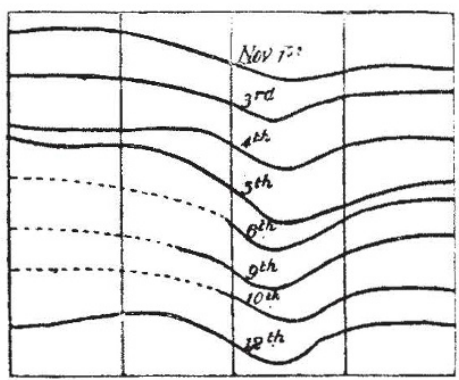

FIG. 9. -Diurnal waves at Shide, I.W., $\mathrm{x} \mathrm{mm}$. deflection $=$ tilt $0^{\prime \prime} \cdot 5$ (Milne.)

direction of greatest movement at the time of an earthquake appears to be at right angles to the dip, from which it may be inferred that valleys due to geotectonic folding exhibit a certain flexibility, tend to support the idea that the observed diurnal movements are due to actual movements of more or less extensive areas. No doubt some portion of the observed effects may be directly attributable to solar radiation.

In searching for an explanation of diurnal, annual and other changes in the vertical, the seismologist has had to consult the records of the astronomer, the observations of the hydraulic engineer, the botanist, and the farmer, and to experiment and search for information in domains far removed from anything supposed to be connected with movements of the ground.

Have changes in the vertical been most pronounced in regions where it may be supposed that orogenic changes are yet in progress? How far are changes in the vertical effected by seasonal and daily changes in temperature, by fluctuations in barometrical pressure, by the rise and fall of tide upon a coast line, and by lunar attraction? What tilting effects would result if the seasonal growth and partial removal of foliage and herbage on one side of an observing station were greater than those upon the opposite side? What is the rate at which alluvium may creep down the face of steep slopes, carrying with it perhaps a forest, and what is its cause? What is the amount of moisture transpired by various plants per day, per month, and per season? Do not some plants and 
trees absorb rather than transpire moisture from the atmosphere at certain seasons? What is the transpiration of plants at night as compared with that during the day? Is there such a thing as subsurface dew, and what is its amount? What is the function of stones in arable land as fertilisers? What do we know respecting the diurnal flow in rivers, and the semi-diurnal rise and fall in certain wells? Will a squad of men walking up to the walls of an observatory, or the load equal to the weight of an average man at the base of a pier in the same produce any appreciable change of level on the top of such a pier? Are high mountains measurably deflected by wind pressure? In the workings of a mine beneath the sea what data do we possess respecting deflections in the roof due to the rise and fall of a superincumbent tide? What is the natural period of vibration of a chimney or building of given structure?

These are examples of the varied questions which have been placed before the seismologist, and to most of which, as the result of experiment and observation, he is able to give fairly definite replies. Although in a few instances these replies may not have given the assistance to his investigations expected, a consolation remains that

\section{R. - Hoves erst from 8 A.M. to 3 or 4 P.M}

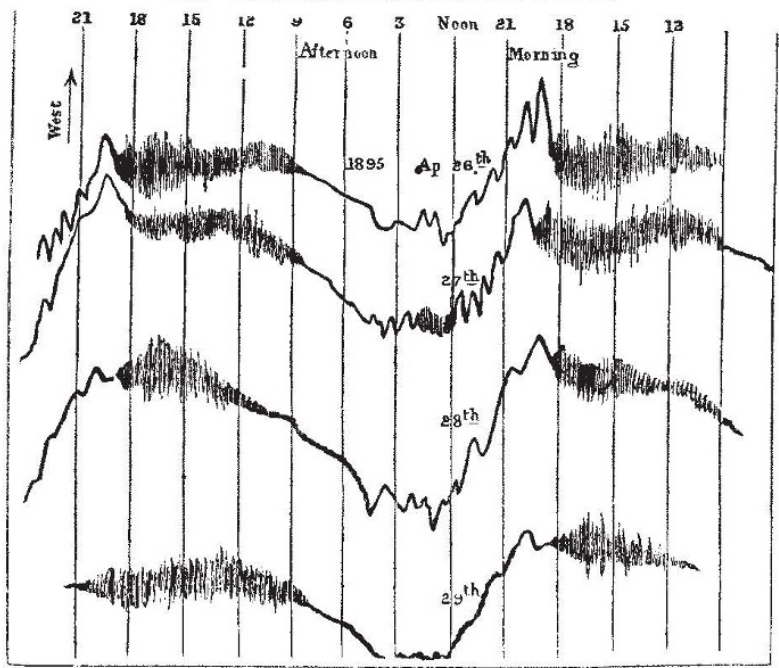

FIG. IO.-Irregular diurnal waves in Japan, always showing tremors from 9 p.m. to 6 a.m. (Milne.)

they have been of considerable value to workers in other fields.

Perhaps the greatest trouble against which the working seismologist has had to fight have been the ubiquitous, so-called, "earth" tremors (see Fig. 10). Sometimes the apparatus will swing, and perform for hours or days various irregular, and sometimes marvellously regular back and forth movements, with the result that all traces of important phenomena have been eclipsed (Fig. I 1). Not only do "tremors" affect finely constructed horizontal pendulums, but in all probability they affect magnetographs, the delicate balance of the assayer, and accelerate or retard the swing of pendulums. They are frequent in winter, at night, and whenever the observatory in which they are recorded is crossed by a steep barometric gradient. They are particularly noticeable with a frost and a falling thermometer. With a howling gale, and even during a typhoon, when buildings shake and shudder, they are as likely to be absent as present (Fig. I2).

Because a light horizontal pendulum is more disturbed than one that is heavy, and that we observe at one station tremors are marked, whilst they are only shown feebly, or are entirely absent at another station a few

yards distant, it is evident that we are dealing with movements due to currents of air, rather than with movements due to tremors in the ground. Although we fully recognise, as stated at the commencement of this article, that there are microseismic movements in the earth, it is very doubtful whether in the thousands of observations carried out day and night, especially in the Italian peninsula, these movements have been differentiated from those which are the result of atmospheric

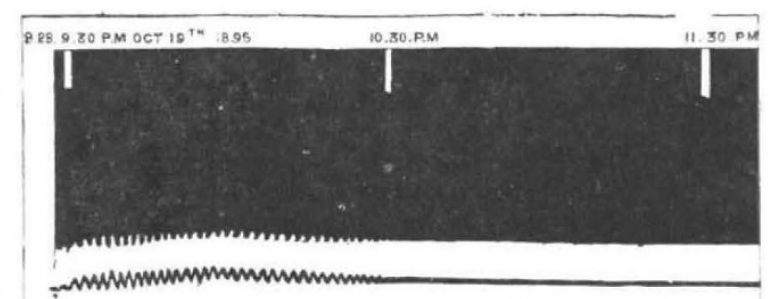

SHIDE

Fig. II -Pulsations or very regular tremors with periods of 2 or 3 minutes. The recording pendulum has always a natural period of about $x_{5}$ seconds. (Milne.)

circulation. Simply opening or closing the door of a case covering an instrument will sometimes start or stop a so-called tremor storm. The fact that placing a tray of calcium chloride insicle one of these cases will cause very large and continuous movements which cease on its withdrawal, indicates that air currents are partly due to the manner in which an atmosphere becomes dry or moist. In the search for the originating cause of tremors

10. PM

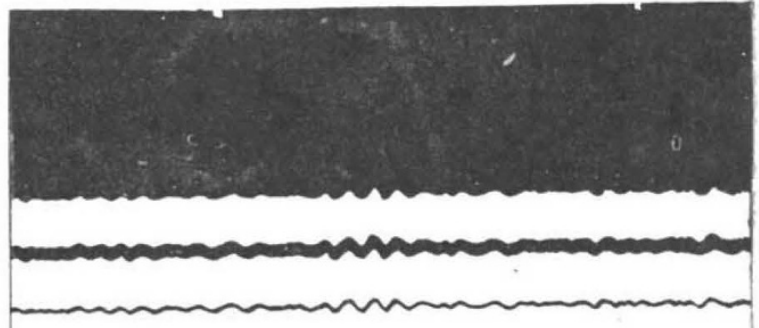

Oct $10^{T H} 1895$

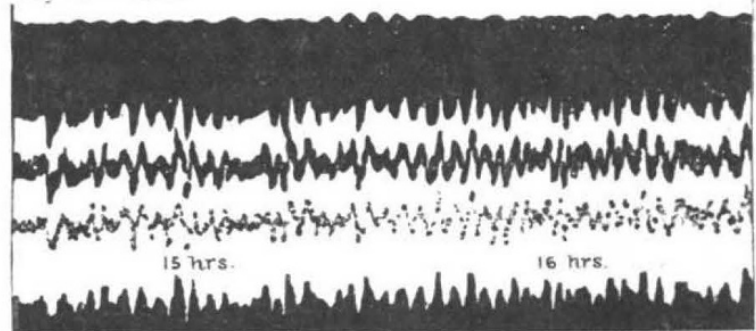

FIG. I2.-Commencement of a tremor storm at ro p.m. with movements having a period of several minutes. At 15 and $I 6$ hours they are very irregular, whilst later the band is blackened by these movements. (Milne.)

which has extended over a period of nearly thirty years, we see an excellent example of long-continued and patient work which, so far as the advancement of seismology is concerned, appears at first sight to have terminated in a fiasco. Now, however, we know that we have to distinguish between movements caused by the atmosphere and those coming from the earth. We see a reason why at particular observatories magnetographs are sometimes on the swing. The reason why,

No. 1473 , VOL. 57$]$ 
under certain conditions, the assayer's balance may sometimes oscillate and quickly change its zero is understood. Possibly these air currents may indirectly have led to the abandonment of the Cavendish experiment at Cambridge, and explain why a very well-constructed horizontal pendulum is never quite at rest.

One very important piece of knowledge for the seismologist lies in the fact that these so-called tremor; can be stopped by using covering cases through which air can circulate, but above all by working in a room that is almost draughty with ventilation. Sometimes a room will be found which it seems impossible to cure, whilst in the adjoining one, for reasons not quite clear, the same instrument will always remain at rest.

It seems as if there existed in rooms which may be fairly similar in appearance slight physical differences of the walls, the floors and ceilings, as, for example, with regard to dampness; so that in one room, in consequence of differences of temperature, power of desiccation and other properties between the different boundaries, we may have a slow circulation of air estab. lished which is inappreciable in an adjoining room. Whether this is the true explanation of the seismic bogey remains for more careful demonstration, but already the writer has learned that with draughty surroundings an instrument will remain at rest, whilst when this condition is neglected, what is apparently a slow and steady circulation of the atmosphere will cause motion. We yet wish to know why these troublesome visitors appear with such regularity at certain hours and seasons (see Fig. 9). One result of what we have learned is that now hundreds of feet of bromide paper have been saved from blackening, and unfelt earthquakes, which otherwise would have been eclipsed, have been clearly recorded.

In the above few notes all that is attempted is to give a scanty outline of the more important branches of work which at present attract the attention of the working seismologist. Other investigations which it is desirable to make relate to the irregular changes in level which are completed in a few minutes or several days, and above all those grander movements, the results of which are exhibited on the surface of our earth in the formation of continental domes and mountain ranges, together with those activities hidden from our view, which have been referred to as processes of secular flow and crush -in all of which we see the parentage of the earthquake.

J. Milne.

\section{THE CAMBRIDGE EXPEDITION TO TORRES} STRAITS AND BORNEO.

DURING the preparation of a monograph on the anthropology of the Torres Straits islanders, I found the notes I had previously made were unsatisfactory on so many points that I decided to go out again in order to render them as complete as possible, though probably a great deal is by this time irretrievably lost.

A Committee of prominent members of the University of Cambridge is co-operating with me, and part of the cost of the expedition will be defrayed by a grant from the Worts' Fund, which is administered by the University -

The expedition will be almost entirely anthropological in character, but the land flora and fauna will not be neglected, and certain geographical observations will also be made.

The other members of the expedition are Dr. W. McDougall, Fellow of St. John's College, Cambridge, and of St. Thomas's Hospital, London; Dr. C. S. Myers, Caius College, Cambridge, and St. Bartholomew's Hospital, London; Mr. S. H. Ray, Dr. W. H. R. Rivers, St. John's College, Cambridge, Lecturer on Experimental Psychology at Cambridge and at University College, London; Dr. C. G. Seligmann, of St. Thomas's Hospital; and Mr. A. Wilkin, of King's College, Cambridge.

$$
\text { NO. I } 47 \hat{3} \text {. VOL. } 57]
$$

The work of the expedition will be distributed as follows :-I shall be responsible for the observations on the physical characters of the natives; their language and phonology will be studied by Mr. Ray. Mr. Ray, who has a world-wide reputation as an authority on the languages of Oceania generally, has already made a very careful study of the languages of Torres Straits " A Study of the Languages of Torres Straits, with Vocabularies and Grammatical Notes," Proc. Roy. Irish Acad. (3), ii., I893, p. 463 ; iv., I897, p. II9). Drs. Rivers, McDougall and Myers will initiate a new departure in practical anthropology by studying comparative experi. mental psychology in the field. They will test the senses and sensibility of the natives as far as it will be possible under the local conditions, and make whatever observations they can on the mental processes of the natives. Dr. Myers will also pay especial attention to native music, and I shall continue my researches on the decorative art of British New Guinea.

The hygienic and medical aspects of anthropology will be studied by the four qualified medical men. The sociology of the natives, including such subjects as re. lationships, ownership, land tenure, descent of property, and the like, will be investigated by Mr. Wilkin. All the old legends that can be collected will be recorded, and an endeavour will be made to recover the old beliefs of the people. Other departments of anthropology will also be studied. Dr. Seligmann will act as naturalist to the expedition; one of his duties will be to identify all the animals and plants which are utilised by the natives in any way.

Besides the ordinary instruments for anthropometry, there will be a small, carefully selected, collection of apparatus for experimental psychology. Two mechanical phonographs will be taken to record the native songs, music and languages. There will also be a complete photographic equipment, including a cinematograph for reproducing native dances, ceremonies, and certain characteristic actions.

The main object of the expedition is to continue and, as far as practicable, complete the earlier observations made in Torres Straits ; but, for the sake of comparison, it is hoped that observations will be made on Australians, Papuans, Melanesians and Polynesians, as opportunities present themselves. After spending a few months in the Straits a short visit will be paid to the mainland of New Guinea, in order to trace the relationship of the islanders.

Some of the party will then have to return home; but the remainder have accepted a very generous and enthusiastic invitation to visit $\mathrm{Mr}$. C. Hose, the Chief Magistrate of the Baram District of the Raj of Sarawak. Mr. Hose, who is a Cambridge man (Jesus College), is a keen naturalist and has a very wide knowledge of the natives and their languages, and has a warm sympathy for the people themselves; consequently the expedition will have exceptional facilities for seeing something of the inland tribes of Borneo, and interesting comparisons may be expected between the different races which the expedition will have under observation.

The expedition will start about March 2, and will return early in the summer of 1899 .

Any suggestions as to lines of investigation or methods of study will be gladly welcomed. If the curator of any museum or collection desires information respecting ethnographical objects from Torres Straits or British New Guinea, and sends sketches or photographs of such objects to me (Inisfail, Hills Road, Cambridge; or Thursday Island, Torres Straits, Queensland), I will take the illustrations with me, and will endeavour to obtain the required information at the spot where the objects were obtained. I shall also be pleased to make, as far as I am able, any special inquiries that any ethnologist may require.
Alfred C. Haddon. 